\title{
China y Rusia en torno a la relación de Argentina con Estados Unidos
}

Roberto Miranda*

\section{RESUMEN}

El objetivo de este artículo es analizar la incidencia de China y Rusia en la relación bilateral de Argentina con Estados Unidos, a fin de evaluar si tal incidencia le aportó poder a la política exterior del país latinoamericano ante la potencia hegemónica. El estudio realizado está centrado en la política exterior de los gobiernos kirchneristas, entre 2003 y 2015. Por un lado, se considera el vínculo de Argentina con Estados Unidos, el cual no se vio afectado por las relaciones entre el país latinoamericano y las potencias no occidentales. Por otro lado, se examina que la proximidad de Argentina con China y Rusia no fue tan decisiva para las necesidades del país como lo creía su gobierno. En conclusión, el gobierno argentino no construyó poder a través de las relaciones bilaterales con la potencia asiática y la euroasiática para sostener su objetivo de decisiones independientes frente a Estados Unidos.
Palabras clave: Argentina, Estados Unidos, China, Rusia, bilateralismo, autonomía.

\section{China and Russia in regards to Argentina's relationship with the United States}

\begin{abstract}
The objective of this article is to analyze the impact of China and Russia on Argentina's bilateral relationship with the United States, in order to assess whether such an impact gave power to the foreign policy of the Latin American country in the face of the hegemonic superpower. The study focuses on the foreign policy of the Kirchnerist governments, between 2003 and 2015. On the one hand, Argentina's link with the United States is considered, which was unaffected by relations between the Latin American country and the
\end{abstract}

\footnotetext{
* Doctor en relaciones internacionales. Investigador principal, Consejo Nacional de Investigaciones Científicas y Técnicas. Profesor de posgrado, Universidad Nacional de La Plata, Universidad Nacional de Rosario (Argentina). [robertoxmiranda@yahoo.com.ar], [https://orcid.org/0000-0001-7692-2253]

Recibido: 11 de junio de 2019 / Modificado: 18 de julio de 2019 / Aceptado: 19 de julio de 2019

Para citar este artículo:

Miranda, R. (2020). China y Rusia en torno a la relación de Argentina con Estados Unidos. OASIS, 31, pp. 167-183 Dor: https://doi.org/10.18601/16577558.n31.10
} 
non-Western powers. On the other hand, it is examined that Argentina's proximity to China and Russia was not as decisive for the country's needs as its government believed. In conclusion, the Argentine government did not construct power across the bilateral relations with the Asian great power and the Eurasian one to support its target of independent decisions towards the United States.

Key words: Argentina, United States, China, Russia, Bilateralism, Autonomy.

\section{INTRODUCCIÓN}

El apogeo del multilateralismo a partir de la posguerra fría y la globalización no fue en desmedro del bilateralismo. Al contrario, esta práctica inherente a la diplomacia creció enormemente hasta el punto que gran parte de la cooperación internacional, como de la integración interestatal, se basó en redes de bilateralismos, en algunos casos bajo formas diferentes al pasado ${ }^{1}$. En las primeras dos décadas del presente siglo la dinámica de las relaciones bilaterales reflejó con mayor claridad el impacto que sobre estas relaciones han tenido, directa o indirectamente, terceros actores estatales $\mathrm{u}$ organizaciones internacionales. $\mathrm{La}$ situación cobró importancia analítica no solo para compulsar la estabilidad y la perspectiva del vínculo entre dos países, también para examinar la elección que uno de estos realiza de otros actores, destinada a lograr mejor posición en el citado vínculo. Principalmente cuando se trata de las relaciones bilaterales de un país periférico con una potencia mundial, regional o bien desarrollada.

El estudio sobre la incidencia de terceros actores estatales o intergubernamentales en determinadas relaciones bilaterales ha cosechado algunos avances interesantes. Uno es el realizado por Bruce Gilley (2011) que en el tratamiento de la relación de Canadá con Estados Unidos a través de la variable diplomática, consideró fructífera la interposición china para la perspectiva internacional de Ottawa y con respecto a su vecino ${ }^{2}$. Otro estudio (Thoker y Sing, 2017) examinó los efectos de la coincidencia de intereses estratégicos entre China, Pakistán y Rusia sobre el curso del bilateralismo de India con Estados Unidos, afanosamente logrado en 2005 y 2009. También es posible mencionar el análisis en torno a la inestabilidad de las buenas relaciones de Australia con Chi-

1 En América Latina tanto el Mercado Común del Sur (1991), como el Sistema de la Integración Centroamericana (1991), la Asociación de Estados del Caribe (1994) y la Unión de Naciones Suramericanas (2008), son esquemas de integración interestatal que previo a sus respectivas creaciones registraron convergencia de diferentes bilateralismos, los cuales le dieron sustentabilidad institucional. El caso del Mercosur fue una consecuencia de la sociedad estratégica entre Argentina y Brasil, mientras que el impulso de Unasur resultó de las fuertes relaciones bilaterales entre Brasil y Venezuela, Venezuela y Argentina y Argentina y Brasil, luego del fracaso del proyecto llamado "Eje del Sur”, de 2005, entre Brasilia, Buenos Aires y Caracas.

2 Se debe tener en cuenta que el análisis de Gilley se editó en 2011, de manera tal que el académico no podía imaginar el episodio reciente del caso Meng Wanzhou (Huawei). 
na y Japón como consecuencia del tenso lazo existente entre Pekín y Tokio (Flanagan, 2017). Por último, se destaca el trabajo de Susanne Gratius (2017) que observó la importancia del papel desempeñado por la Unión Europea en el conflicto y posterior acercamiento de Cuba con Estados Unidos, como en la relación del gobierno de La Habana con Venezuela.

La citada literatura académica, si bien es diversa en cuanto a las situaciones estudiadas y a los puntos de vista volcados sobre las mismas, tiene el común denominador de indagar el grado de afectación que terceros actores provocan alrededor de un vínculo bilateral, como así también el tipo de beneficio o perjuicio que tales actores le provocan al país más débil o menos poderoso de aquel vínculo. En este sentido se trata del análisis de las posibilidades del país periférico de manejar los intereses que "planta" una potencia en el juego del bilateralismo, adaptándose a las tendencias favorables presentadas por este juego, o bien limitando las desfavorables (Hurrell, 2013, p. 39). El papel de terceros actores está asociado al postulado de que los países más poderosos no siempre pueden imponer su voluntad a los menos poderosos. En palabras de Brantly Womack (2004, pp. 360-361) "el poder relativo no es igual a un poder absoluto". De esta forma una de las alternativas para el país periférico es que la irrupción de terceros actores puede ser clave para disponer de apoyo exógeno en la relación bilateral con un actor más fuerte.

El contar con el mencionado respaldo externo aporta a la construcción autonomista de la política exterior de todo país periférico. Entre otros motivos porque refuerza el eje heterodoxo de la autonomía que es el discrepar con la potencia hegemónica en custodia de los intereses nacionales, sin contrariar el liderazgo estratégico de tal potencia (Puig, 1971). El crecimiento de las relaciones bilaterales con otros actores de relevancia mundial diferentes al hegemón, implicaría para el país periférico adicionar cierto poder. Un poder que hipotéticamente mejoraría su posicionamiento internacional, y al mismo tiempo contribuiría a desplazar el vínculo con el hegemón hacia un lugar de mayor holgura para aquel país, bajo la expectativa de reducir la dependencia del mismo. El supuesto es que sobre la agenda bilateral entre el país dominante y el país periférico, el incremento de la simbiosis de este actor con potencias amenazantes al liderazgo hegemónico, va a incidir considerablemente en aquella agenda.

Argentina ha sido uno de los países periféricos que encaminó las relaciones bilaterales con China y Rusia para tratar de encontrar fortaleza política ante Estados Unidos ${ }^{3}$. A través de este intento buscó incrementar su nivel de influencia, separadamente de la potencia

\footnotetext{
3 Vale subrayar que a partir de 2013, durante el segundo gobierno de Cristina Kirchner, fue evidente el refuerzo del acercamiento de Argentina con China y Rusia en un momento en el cual la relación entre Buenos Aires y Washington era tensa. Al respecto, sin más, ver Elsa Llenderrozas (2011), Francisco Corigliano (2011) y Constanza Mazzina y Manuela González Cambel (2018).
} 
hegemónica aunque con efecto explícito sobre la misma, aprovechando el contexto internacional globalizado que Andrew Hurrell (2016, pp. 7-8) analizó como benigno para países emergentes y no occidentales. A esta expresión se añade el supuesto de que todo aumento de peso político de un actor contribuye a modificar la interacción hacia otro actor (Schunz, 2010, p. 25). El gobierno argentino, durante las gestiones kirchneristas entre 2003 y 2015 , entendió esa posibilidad derivada de aquellas relaciones bilaterales para re-acomodar su vínculo con Estados Unidos. Esta voluntad estuvo movida por el propósito de descomprimir dependencia y, al mismo tiempo, recomponer las prioridades y expectativas de política exterior poniendo el foco en otras potencias mundiales ${ }^{4}$.

El objetivo de este artículo es analizar la incidencia de China y Rusia en la relación bilateral de Argentina con Estados Unidos, a fin de evaluar si tal incidencia le aportó poder a la política exterior del país latinoamericano ante la potencia hegemónica. La metodología utilizada para cumplir con el citado objetivo se basó en un tipo de estudio descriptivo, teniendo en cuenta la modalidad correlacional. A tal efecto se indagó sobre las características de las relaciones bilaterales de Argentina con Estados Unidos para identificar las cuestiones principales que determinan tales relaciones. Por otra parte, se examinó el comportamiento de Argentina ante el comportamiento que China y Rusia tuvieron con ella a través de sus respectivas políticas exteriores. En estos dos casos se trabajó el grado de relación de Argentina con cada una de las potencias no occidentales en torno a la intensidad, densidad, alcance y limitaciones de las vinculaciones bilaterales. La información obtenida se evaluó a través de una variable relacional, descartando por razones de espacio variables individual, contextual y referencial. De este modo, se analizó la posición de China y Rusia en la agenda externa argentina con respecto a la posición de Estados Unidos en esa agenda, y en consecuencia se determinó el nivel de incidencia de la potencia asiática como de la euroasiática en el lazo entre Buenos Aires y Washington.

Los resultados de la investigación se vuelcan en distintas secciones. En la primera de tales secciones se desarrolla la relación de Argentina con Estados Unidos. Luego, se estiman y valoran dos aspectos fundamentales. Uno es el tratamiento de la repercusión de las relaciones de Argentina con China y Rusia en

4 La perspectiva teórica de la autonomía producida por Juan Carlos Puig (1971), Helio Jaguaribe (1979), Guillermo Figari (1985), Francisco Gil Villegas (1989) y Andrew Hurrell (2013), por citar algunos académicos representativos de tal perspectiva de distintas épocas y diferentes países, coinciden -en términos sustanciales- que el concepto de dependencia es una invariante sistémica de la lógica del poder de las potencias mundiales y de la lógica estructural de las economías desarrolladas. La dependencia de un país periférico es principalmente económica, militar y tecnológica. El peso de una sobre la otra está relacionado con el contexto en el cual se desarrolla la relación entre el país periférico y la gran potencia. Descomprimir dependencia no es otra cuestión más que la de generar alternativas para alcanzar autonomía, lo cual podría ser -por ejemplo- morigerar la subordinación tecnológica con una gran potencia a través de la diversificación de las relaciones exteriores. 
torno al vínculo entre Buenos Aires y Washington. El otro aspecto se refiere al abordaje sobre el poder que para Argentina significó el refuerzo del lazo establecido con Pekín y Moscú. Todas las cuestiones analizadas tienen como referencia hipotética que las relaciones con China y Rusia, en el período estudiado, no representaron para Argentina una dosis de poder para el ejercicio de la autonomía frente a la potencia hegemónica.

\section{ENTRE LA CERCANÍA Y EL DISTANCIAMIENTO}

Una vez que a principios de este siglo Argentina inició negociaciones para superar su morosidad en los pagos de deuda externa, configuró una agenda bilateral mínima con Estados Unidos basada en el curso de estas negociaciones. Se gestó una relación a la que se puede denominar de cercanía forzada. Por un lado, Argentina necesitó dejar atrás su estado de indefensión internacional ${ }^{5}$ y, por otro, el gobierno estadounidense decidió participar de las mencionadas negociaciones para evitar un efecto dominó en la región, después de haber sido indiferente hacia la situación en la que se encontraba el país latinoamericano. Adquirió una participación bastante decisiva hasta el punto de conducir el proceso negociador, apartando a Anne Krueger, subdirectora del
FMI (Fondo Monetario Internacional), como a Lawrence Lindsey, consejero económico de la Casa Blanca, ambos de postura muy dura hacia Argentina, y centrando toda la responsabilidad del éxito de tal proceso en John Taylor, subsecretario para Asuntos Internacionales del Departamento del Tesoro (Miranda, 2014, pp. 234-236).

Argentina supo del costo que debió afrontar como deudor, lo consideró contingente, $y$ se adaptó a las reglas del rol desempeñado por Taylor para brindar respuestas a los acreedores, sabiendo de su reducido margen de maniobrabilidad internacional. Al respecto el gobierno de George Bush tuvo una política de "complicidad”, por llamarlo de algún modo. Apoyó al presidente Néstor Kirchner, los productos argentinos no fueron excluidos del Sistema Generalizado de Preferencias y el Departamento de Estado brindó declaraciones de respaldo al país latinoamericano. Más aún, hubo otras dos cuestiones muy representativas de la mencionada "complicidad" estadounidense. Por un lado, Argentina no fue incluida en el listado de países desinteresados en acompañar a Bush en la invasión a Irak y, en consecuencia, vetados de acceder a pertrechos militares del hegemón. Por otro, el juez Thomas Griesa frenó los embargos a cuentas y bienes del Estado argentino "protegiendo" el curso de las negociaciones.

\footnotetext{
5 La noción indefensión internacional suele estar relacionada con cuestiones de defensa o seguridad, también con aspectos jurídicos de tipo humanitario. El hablar de indefensión internacional de Argentina se refiere a la época de la crisis del default de 2001. En esa circunstancia, su irrelevancia estratégica y económica, como su vulnerabilidad externa (de Estado débil, matriz productiva quebrada y sociedad empobrecida), la transformaron en un país internacionalmente inerme (Miranda, 2003, p. 6).
} 
Del entendimiento mutuo entre Buenos Aires y Washington, uno por su resiliencia y otro por su connivencia, derivó el comienzo del desendeudamiento argentino y el resguardo estadounidense del sistema financiero internacional. Roberto Lavagna, ministro de Economía, y Taylor, coronaron aquella cosecha extremadamente vital para Argentina en un año, 2005, en el cual parecía que las relaciones bilaterales iban camino a su consolidación. El gobierno argentino creyó abrazar una "posición equilibrada" entre "posturas aislacionistas" y "opciones de alineamiento" (Torres, 2013, p. 115). El esquema de financiación de vencimientos de deuda, como la propuesta de canje a acreedores privados de bonos en default y la cancelación del pasivo con el FMI, permitieron que la agenda bilateral se ampliara. El gobierno argentino ratificó dos instrumentos de lucha contra el terrorismo, uno de la Asamblea General de Naciones Unidas y otro de la Asamblea Plenaria de la Organización de Estados Americanos, y se comprometió en el combate contra el narcotráfico accediendo a modificar la ley sobre lavado de dinero, conocida como Ley Carrió.

También en 2005 el gobierno argentino dio muestras de su buena relación con Estados Unidos al normalizar los ejercicios militares conjuntos, la participación en la Misión de $\mathrm{Na}$ ciones Unidas para la Estabilización de Haití y el rechazo explícito a la proliferación nuclear. Pero lo más importante para Washington fueron dos cuestiones. Por un lado, el reclamo de Argentina a Irán con el fin de que algunos de sus ciudadanos comparecieran ante la justicia al estar bajo sospecha de tener responsabilidades en el atentado a la AMIA (Asociación Mu- tual Israelita Argentina), ocurrido en 1994. Por otro, el desistimiento del gobierno argentino a denunciar los 59 tratados bilaterales sobre Promoción y Protección Recíproca de Inversiones, firmados entre 1990 y 2000, los cuales eran muy ventajosos para los inversores como el acuerdo sellado con Estados Unidos, que entró en vigencia en 1994.

Resuelto gran parte del defaulty gracias a la recuperación económica, mayormente sostenida por los altos precios de las commodities, como por los abultados volúmenes de exportación de soja, el gobierno argentino imaginó que había logrado un soporte suficiente para impulsar políticas autonomistas destinadas al "desarrollo sustentable" y a la reinserción internacional del país a través del Mercosur. Con base en esta creencia, fortalecida por la victoria electoral de medio término, la relación con Estados Unidos se planteó desde otra perspectiva tratando de demostrar que Argentina había alcanzado independencia decisional, y por lo tanto el nivel de presión de Washington sobre la agenda bilateral iba a ser considerado de manera diferente a como había sido tratado hasta ese momento. Para algunos analistas Argentina iniciaba una "oposición limitada" a Estados Unidos (Russell y Tokatlian, 2013, p. 253), mientras que para otros la relación bilateral retornaba a los desencuentros del pasado (Falcoff, 2004, p. 78). La idea presidencial de entonces era la de inhibir el influjo estadounidense y de las instituciones financieras internacionales.

Hubo dos situaciones por medio de las cuales la relación bilateral entre Argentina y Estados Unidos ingresó en un escenario de tensión. Una fue la IV Cumbre de las Américas 
realizada en Mar del Plata, en noviembre de 2005, en la que el gobierno argentino facilitó la organización, en paralelo, de un evento antiestadounidense en el cual el presidente venezolano, Hugo Chávez, estuvo en el centro de las críticas al hegemón. Este acontecimiento fue bisagra de enemistad entre ambos países, y no así el rechazo al proyecto promovido por Washington sobre el Alca (Área de Libre Comercio para las Américas), como suele mencionarlo alguna que otra literatura académica. La Casa Blanca no tipificó esta oposición de Argentina y Brasil como un desafío. Por ejemplo, Bush, después de Mar del Plata, visitó al presidente brasileño Luiz Inácio Lula da Silva y lo invitó a su país, acontecimiento que se produjo en Camp David, en marzo de 2007, ámbito al cual suelen asistir solo gobernantes de países que Estados Unidos considera socios estratégicos.

La otra situación de tensión en la relación bilateral fue en ocasión de la visita a Buenos Aires de Nicholas Burns, subsecretario de Estado para Asuntos Políticos, en febrero de 2007. El funcionario estadounidense portaba el pedido del Congreso de su país de presionar a Argentina y Brasil para que aislaran internacionalmente a Venezuela por su involucramiento en los procesos electorales de 2006 de Bolivia, Nicaragua y Perú. Kirchner rechazó esta petición, y en consecuencia la relación perdió estabilidad. Bush, la oposición demócrata y la prensa gráfica comenzaron a rotular de "caudillista" al presidente argentino. Estados Unidos apartó a Argentina y no a Brasil de las giras que luego realizaron a través de la región, por separado, Bush, Burns y Condolezza Rice, secretaria de Estado. Claro que Brasil era un Estado-pivot del hegemón, por lo tanto la valoración de este fue muy distinta a la realizada sobre Argentina. Sin embargo, para Kirchner tal distinción no fue importante, sintió que el país había "ganado autonomía” frente a las presiones estadounidenses.

\section{UN GIRO DIPLOMÁTICO}

La ilusión que despertó en el gobierno argentino la llegada del demócrata Barack Obama a la Casa Blanca, en enero de 2009, rápidamente se esfumó. Obama continuó con la política busheana de penalización de Argentina que consistió en investirla de chavismo dada la compatibilidad política y las relaciones interpersonales entre Kirchner, la presidenta Cristina Kirchner y Chávez. Era una época en la cual sobrevolaba el efecto del conflicto diplomático que se había producido en torno al caso de la "valija" de Guido Antonini Wilson, portadora de dólares proveniente de Caracas supuestamente para la campaña electoral de la presidenta. Un episodio que la memoria estadounidense sumó a lo ocurrido en la cumbre de Mar del Plata, asociando a Argentina con Venezuela y reforzando la postura de restarle valor al país rioplatense en su agenda hemisférica. Para Peter Hakim, presidente de Diálogo Interamericano, estaba claro que Estados Unidos había dejado de tener en cuenta a Argentina ${ }^{6}$. 6 The New York Times. (13/03/2008). Rice Trip to Skip Argentina in Sign of a Growing Rift. October 19, 2011.
Disponible en https://www.nytimes.com/2008/03/13/world/americas/13rice.html 
Una de las excusas de la penalización fue la negativa a negociar con los bonistas disidentes del canje realizado en 2005, los cuales organizaron el lobby político American Task Force Argentina, junto a la Asociación de Ganaderos de los Estados Unidos (USCA), que ejerció influencia en torno al Capitolio y al Departamento de Estado para exigirle a Buenos Aires el pago del total de la deuda. Otra excusa fue la reticencia de Argentina a cumplir, como miembro del FMI, con el artículo IV del estatuto relativo a la supervisión de las políticas económicas, sobre todo de los tipos de cambio. Se añadían dos pretextos más. Uno era el incumplimiento argentino de casos resueltos por el Ciadi (Centro Internacional de Arreglo de Diferencias Relativas a Inversiones) de dictámenes negativos, y el otro pretexto era la deuda con el Club de París.

La consecuencia directa o indirecta, según se la analice, fue que la inversión transnacional evitó desembarcar en territorio argentino. La recomendación de la burocracia estatal estadounidense de esquivar tal desembarco no fue la única, también grupos financieros de Wall Street y think tank siguieron esta sugerencia. Sin embargo, la opinión gubernamental de Washington gravitó de manera considerable al etiquetar a Argentina como un país jurídicamente inseguro, apegado al molde populista. The Washington Post reproducía esta aproximación hasta el punto de establecer una semejanza de Kirchner con Chávez ${ }^{7}$ La actitud del gobierno argentino de exhibir su convencimiento de separación de Estados Unidos y de los medios financieros multilaterales, contrarió la intención de atraer inversiones al país. Fue notorio en ocasión de la visita de los Kirchner a la Bolsa de Valores de Nueva York, en 2006. Lo mismo sucedió cuando Cristina Kirchner se acercó a Wall Street, en 2010. En ambos casos, por encima de la tradición y del protocolo, el mensaje argentino a los inversores transnacionales no tuvo eco. Para algunos analistas, los "ataques discursivos" de los gobernantes argentinos destinados a Estados Unidos y las instituciones financieras internacionales, tuvieron que ver con la mencionada indiferencia del mercado (Sullivan y Nelson, 2015).

A pesar de esta situación tan decisiva en la relación bilateral, hubo un momento en el cual existieron indicios ciertos de que el acercamiento entre ambos países era posible. Después de no concretarse la reunión propuesta por Cristina Kirchner a Obama durante la III Cumbre del G-20, realizada en Pittsburgh en setiembre de 2009, hubo tres oportunidades a través de las cuales era presumible la mejoría en el bilateralismo. Una fue la visita a Buenos Aires de la secretaria de Estado, Hillary Clinton, a principios de 2010. Si bien tal visita adquirió un tono neutro, igualmente representó el aflojamiento de la discordia entre ambos países. Otra circunstancia, también en

The Washington Post. (26/12/2007). A Bagman's Tale; Did Hugo Chavez Purchase the Allegiance of Argentina's New Presidente? June 17, 2011. Disponible en http://www.washingtonpost.com/wp-dyn/content/article/2007/12/25/ AR2007122500871.html 
2010, fue el encuentro que Obama finalmente le concedió a la presidenta argentina durante la Cumbre de Seguridad Nuclear, llevada a cabo en Washington. Por último, a fines de 2011, en ocasión de la VI Cumbre del G-20, en Cannes, Cristina Kirchner y el presidente estadounidense volvieron a tener una nueva tertulia, y al mismo tiempo cruzaron elogios y reconocimientos mutuos que anticipaban la eventualidad de una relación encaminada.

Sin embargo, el momento de una posible aproximación entre los dos países fue efímero. En la agenda bilateral pesaron cuestiones más fuertes que las declaraciones y las expresiones emotivas que se habían dispensado ambos gobernantes. Una de esas cuestiones ocurrió en 2010 cuando el gobierno argentino violó el principio de confidencialidad de información de inteligencia de la FinCen (Red de Combate de Crímenes Financieros) del Departamento del Tesoro, dedicada al monitoreo de operaciones financieras de personas y empresas en torno a procesos de lavado de dinero y de origen dudoso. Otra fue la interceptación directa de la Cancillería de un avión militar estadounidense en el aeropuerto de Ezeiza, en 2011, con la sospecha de portar "material sensitivo", cuando en realidad la carga estaba destinada a programas de capacitación de personal de la Policía Federal. Por último, también en el citado año, uno de los temas tal vez más relevante de la relación bilateral fue el inicio de la negociación entre Argentina e Irán de un Memorándum de Entendimiento sobre el asunto judicial del atentado a la AMIA.

La mencionada negociación significó no solo un giro de la diplomacia argentina, la cual hasta esta instancia le había reclamado a Irán colaboración para que sus funcionarios acusados por la justicia se presentaran ante la misma, también tal negociación alentó la hipótesis estadounidense del triángulo entre Buenos Aires, Caracas y Teherán vinculada a la venta de tecnología nuclear. Washington conjeturaba que Argentina podía abastecer a Irán de la citada tecnología mediante la intermediación de Venezuela. Por encima de los alegatos esgrimidos por Estados Unidos para bloquear el acceso argentino a la inversión transnacional, comentados más arriba, y de las cuestiones de tirantez habidas entre ambos gobiernos, la firma del Memorándum de Entendimiento -en enero de 2013- fue un acontecimiento que profundizó aún más el distanciamiento bilateral. Es posible deducir que simbolizó el comienzo de otra etapa de la política exterior argentina. La segunda operación de canje de bonos en default, en 2010, como el pago que el gobierno argentino hizo tres años después de casi 700 millones de dólares a cinco empresas sobre laudos firmes dictados por el Ciadi, no logró modificar la actitud de alejamiento forzada por Washington. Tampoco el acuerdo que Buenos Aires selló en 2014 con el Club de París, abonando en 5 años casi 10 mil millones de dólares de deuda con este grupo.

Cristina Kirchner, consolidada políticamente en 2011 por su reelección como presidenta con un amplio caudal de votos, reflotó la creencia de 2005 de que Argentina -gracias a la independencia decisional- había logrado desplazar a Estados Unidos del centro de su política exterior. Sin embargo, la concentración de las relaciones bilaterales en Brasil y Venezuela, junto a la participación en el multilateralismo sudamericano institucionalizado 
por medio de Unasur (Unión de Naciones Suramericanas) y el reencuentro político con México una vez que Felipe Calderón asumió la presidencia, no fueron cimientos suficientes para continuar sosteniendo aquella creencia. El gobierno argentino necesitaba de actores más poderosos y a la vez rivales de Estados Unidos, de aquellos que le discutían a este la política mundial compitiendo por un mayor ascendiente en distintas regiones del planeta, y por un mayor control del curso de las relaciones internacionales. Actores que contribuyeran a moderar el efecto del distanciamiento que Argentina tenía con el hegemón siendo parte de su esfera de influencia, lo cual no era un detalle menor.

\section{EL PARALELISMO}

La presencia cada vez más acentuada de China y Rusia en América Latina, fue uno de los datos relevantes arrojado por la política regional en el presente siglo, y Argentina no estuvo al margen de las avanzadas que ambas potencias desarrollaron con diferentes países, sobre todo sudamericanos. Los objetivos y las estrategias de Pekín y de Moscú para Latinoamérica en general y para Argentina en particular, si bien fueron notoriamente distintas, coincidieron en aprovechar el desinterés de Occidente por la región (Leiteritz, 2012; Pavlova, 2011). La recesión económica acaecida en Estados Unidos después de la sobreproducción de tecnologías de la comunicación, más el golpe terrorista del 11-S y la crisis financiera internacional de 2008 por la cual hubo serias discrepancias entre las potencias occidentales, habían puesto a América Latina fuera del foco de atención de estas potencias. A través de los lazos con China y Rusia, algunos países de la región experimentaron que había otro "mundo" y otras relaciones exteriores posibles.

El acercamiento impulsado por las mencionadas potencias no occidentales representó una opción cierta para la política exterior argentina. Opción que cobró fuerza cuando Argentina y Estados Unidos pactaron, tácitamente, un claro desapego de la agenda bilateral. Así, las relaciones de Buenos Aires con Pekín y Moscú estuvieron libres de obstáculos serios, más allá de la relativa preocupación exhibida por el Congreso estadounidense frente al "desembarco" chino en Sudamérica y a los vínculos "especiales" de Rusia con determinados países latinoamericanos. De manera que gracias a la permisibilidad del contexto internacional, el nivel de cooperación interestatal alcanzado por Argentina, tanto con China como con Rusia, fue claramente significativo, en el primer caso por el predominio de la densidad de cuestiones comunes atesorada a través de la agenda bilateral, y en el otro caso por lo valioso de la intensidad política acuñada entre ambos países. Uno de los aspectos que sobresalió de los citados lazos, de interés en el presente estudio, es que los mismos no afectaron las relaciones de Argentina con Estados Unidos.

China representó para Argentina la "solución económica”, mientras que Rusia fue una suerte de antídoto destinado a limitar, indirectamente, la presión estadounidense. El aumento del precio internacional de la soja y la demanda del país asiático de grandes volúmenes de la oleaginosa, le permitieron recuperar su capacidad exportadora y con ella el crecimiento económico. Entre 2003 y 2007 creció 
por debajo de China, India y Venezuela, pero por encima de Brasil, Chile, Indonesia, Malasia y México, como ejemplo de lo sucedido con algunos países de commodities. En ese período Argentina se transformó en una potencia agrícola que cada año le redituó alrededor de 10 mil millones de dólares de saldo superavitario en la balanza comercial. El apogeo tuvo un parecido a lo experimentado por Argentina en la década de los noventa del siglo XIX y las primeras de la siguiente centuria por medio de la relación con Europa en general y con Gran Bretaña en particular (Escudé, 2011). En el caso del comercio bilateral con China, también como en aquella época hubo complementariedad, en 2010, casi el 80\% de lo exportado al país oriental fue soja y derivados, y Argentina importó el mismo porcentaje en telefonía, informática, productos químicos y motos.

La participación de Pekín sobre el comercio exterior de Argentina fue de alto impacto al modificar sustancialmente la estructura de este comercio, hasta el punto que China escaló posiciones que en 2011 la ubicaron en el segundo lugar como compradora y abastecedora del país latinoamericano. Si bien el comercio bilateral no estuvo exento de roces entre ambos países, como cuando Argentina impuso restricciones a las importaciones chinas en once sectores de la economía por la invasión de productos orientales a partir de 2005, la matriz de transacciones de mercancías sellada por Buenos Aires y Pekín fue la garantía para que el vínculo prosperara en otras cuestiones importantes. Por ejemplo, la firma del Memorándum de Entendimiento de 2004, por medio del cual Argentina reconoció que China tenía una economía de mercado, como los acuerdos de swap de 2009 y 2014, cada uno de más 10 mil millones de dólares, el financiamiento para la construcción de dos represas hidroeléctricas en Santa Cruz, y las inversiones del país asiático en petróleo (a través de la empresa estatal CNOOC, la compra del $50 \%$ de Bridas Corporation) y en explotación minera, incrementados los desembolsos sobre esta a partir de 2011.

La relación de Argentina con Rusia fue diferente a la que tuvo con China. El interés político que aunaron Buenos Aires y Moscú fue más decisivo que el interés económico. Argentina percibió a Rusia como una alternativa política frente a las diferencias que guardaba con potencias occidentales, sobre todo en relación con Estados Unidos. Precisamente creyó que el vínculo con el país euroasiático era un camino probable para reducir la dependencia de Occidente. A partir de 2007 el bilateralismo ruso-argentino ingresó en una etapa de gran acercamiento (Yákovlev, 2010), luego del desencuentro que se produjo como consecuencia de las medidas prohibitivas impuestas por el gobierno argentino a la exportación de carne a Rusia. Las necesidades políticas de Cristina Kirchner en 2008 y el protagonismo ruso de esa época gracias a su victoria militar en Georgia, abrieron curso a un mayor nivel de amistad entre ambos países que derivó en el compromiso de una Asociación Estratégica, como resultado de la visita de la presidenta argentina a Moscú en aquel año y la del presidente Dimitri Medvédev a Buenos Aires, en 2010.

Las discordias con Estados Unidos, en el caso de Argentina por la indiferencia de Washington ante la litigiosidad de los holdouts, y en el caso de Rusia por las divergencias sobre el papel de las Naciones Unidas en la guerra de 
Siria, fueron un factor que reforzó aún más la amistad entre la Casa Rosada y el Kremlin. Las coincidencias se acrecentaron hasta la coronación de dos instrumentos diplomáticos bastante demostrativos de la armonía alcanzada. Uno fue el Memorándum de Entendimiento de 2011, por medio del cual se obligaron al Plan de Acción para ejercer "interacción política" con el fin de coordinar posiciones comunes en medios multilaterales. Otro instrumento fue la elevación del tipo de relación entre ambos países al de Asociación Estratégica Integral, con todo lo que ello implicaba. Con estos instrumentos como telón de fondo, Argentina y Rusia cruzaron fuertes respaldos políticos. Por un lado, la abstención argentina en la votación de la Asamblea General de las Naciones Unidas que había considerado "no válido" el referéndum realizado en Crimea bajo el auspicio ruso. Por otro, el aval del presidente Vladimir Putin a Argentina por el conflicto de las Islas Malvinas y la invitación a asistir a la VI Cumbre del grupo Brics realizada en Fortaleza, en 2014.

\section{LO POSITIVO Y LO NEGATIVO}

A pesar de las muy buenas relaciones bilaterales de Argentina con China y Rusia, el vínculo entre Buenos Aires y Washington, como se afirmó antes, no se vio perturbado por tales relaciones. China, como lo hizo en la mayor parte de Sudamérica, ocupó el lugar que Estados Unidos descuidó. En algunos casos el hegemón reaccionó sobre las consecuencias de su desatención, por ejemplo, cuando Argentina consintió en 2015 la instalación de una estación espacial dependiente del ejército chino en la Provincia de Neuquén, la cual se justificó para el monitoreo del lado oscuro de la luna, aunque sospechada de contar con tecnología dual. Precisamente la preocupación del gobierno estadounidense estuvo enfocada en el celo por la cuestión estratégico-militar, no así en la sociedad comercial de Argentina con China aun sosteniendo que la misma perjudicaba a sectores industriales del país latinoamericano, como tampoco en la "interacción política” establecida entre Buenos Aires y Moscú, a la cual consideraba un efecto del patrocinio mutuo librado por los gobiernos de Cristina Kirchner y Putin frente a las potencias occidentales.

Argentina estimó que los lazos con China y Rusia le habían ensanchado el margen de maniobrabilidad internacional. En otras palabras, que le habían brindado poder para moverse con más libertad en sus relaciones exteriores, y de este modo alcanzar mayor gravitación política. Ciertamente el país asiático colaboró para que Argentina recobrara poder material gracias al comercio bilateral, el cual la facultó a quebrar el esquema de doble dependencia arrastrado desde los noventa con Estados Unidos y Brasil. Al mismo tiempo la alianza con Rusia le fue útil al gobierno argentino porque lo ayudó a extender los puntos de apoyo internacional que Occidente le retaceaba, teniendo muy en cuenta la consolidación del reposicionamiento del país euroasiático en el mundo en virtud de los éxitos políticos de $\mathrm{Pu}$ tin. Sin embargo, además de no repercutir en el vínculo de Buenos Aires con Washington, como se señaló más arriba, una y otra relación estuvieron lejos de proporcionar a Argentina el poder que el gobierno presumió.

Si bien la relación con China fue progresiva y estable, se trató de una cooperación bá- 
sicamente comercial de base hegemónica, pues Pekín decidió qué quería de Argentina, es decir, qué función debía desempeñar en la estructura bilateral sobre la cual el país asiático tenía el dominio. Un caso clásico de dependencia del Sur con respecto al Norte (Sevares, 2007). Le asignó el papel de abastecedora de soja y el de cliente comprador de bienes de consumo. Así Argentina adormeció su economía por medio de la re-primarización de la misma (Bekerman y Cerdeiro, 2007; Costantino, 2013). La política de diversificación externa aumentó destinos para las exportaciones sin incrementar el número de productos a vender en el mundo, menos aún con valor agregado.

Lo que comenzó como interdependencia asimétrica se procesó como dependencia. Cuando China priorizó sus intereses, se negó a comprar títulos de deuda argentina, recurrió a represalias dejando de comprar aceite de soja, transformándose en socio de Brasil en este producto sobre el cual originariamente se había comprometido con Buenos Aires, desistió de acompañar la promoción del "desarrollo sustentable" soñado por los gobiernos kirchneristas, y no buscó negociar la reducción de la creciente y muy amplia brecha en la balanza comercial, que desde 2008 le fue favorable sin solución de continuidad.

Como se afirmó más arriba, la relación de Argentina con Rusia fue diferente a la entablada con China, entre otras cuestiones, por la impronta que supo imponer Putin por medio de su estilo marcadamente pragmático. Lo que hizo el presidente ruso fue brindarle resguardo a la política exterior del gobierno argentino, reservándole un lugar en su agenda internacional cada día más relevante. Si bien ambos países sostuvieron una relación simétrica, creciente y duradera, fue Rusia quien propuso y condujo tal relación. De algún modo, Buenos Aires siguió el comportamiento internacional de Moscú, lo cual contrariamente a lo que podría suponerse no representó costo alguno para Argentina. Sin embargo, fue evidente que Putin circunscribió los alcances y los límites de la cooperación bilateral de acuerdo con las coyunturas del contexto internacional y de su propia política exterior.

De manera que la mayor parte de las promesas pactadas quedó pendiente. No hubo un aumento significativo del intercambio comercial como se había acordado, y Argentina se vio imposibilitada de revertir el déficit que acusaba entre 2011 y 2015 (Shcherbakova, 2016). Rusia demostró que Argentina no era comercialmente importante como lo había sido durante varias décadas, a lo cual añadió su desinterés por volver a comprar carne de este país, prefiriendo continuar con el abastecimiento de Brasil y Uruguay. También estuvo lejos de incrementar su papel de inversor, más allá de las expectativas generadas en torno a la central nuclear de Atucha III y del yacimiento de shale Vaca Muerta. Pero lo notable fue cuando Putin, dada su visión estratégica, de una solidaridad discursiva a favor de Argentina por la litigiosidad de los holdouts e indiferencia de Obama, pasó a una tibieza actitudinal en 2013 en ocasión de la VIII Cumbre del G-20, realizada en San Petersburgo. En ese foro, el gobierno argentino no encontró en Rusia el respaldo diplomático que precisaba frente a las potencias occidentales.

Las relaciones de Argentina con China y Rusia fueron relaciones "controladas" por 
Pekín y Moscú, de acuerdo con lo que representaba el país latinoamericano para sus respectivas políticas exteriores. El escaso poder que Argentina reunió por medio de su vínculo con el país asiático, fue una consecuencia directa de la dependencia comercial gestada en el presente siglo ${ }^{8}$. La ampliación de la agenda bilateral mediante temas no comerciales respondió más a las necesidades chinas y menos a las necesidades de Argentina. Por otra parte, el gobierno argentino, en su relación con el ruso, no acopió poder, lo que hizo fue asociarse a la dinámica y pujanza de la "política multivectorial" de Putin, la cual buscaba reeditar la condición de "gran potencia" para el país euroasiático (Leiva Van de Maele, 2017). Argentina pensó que la simpatía por tal propósito le retribuiría una mejor posición política para discutir y saldar favorablemente sus problemas con las potencias tradicionales. Pero esto no sucedió. Las relaciones de poder y de acomodación de intereses entre potencias occidentales y no occidentales, estuvieron muy por encima de las aspiraciones y expectativas de un país periférico como Argentina.

\section{CONCLUSIÓN}

La relación de Argentina con Estados Unidos osciló entre la cercanía y el distanciamiento, predominando la tendencia hacia el desencuentro y la indiferencia mutua. Sobre este escenario irrumpió China que en muy poco tiempo se transformó en uno de los ejes de la política exterior argentina, siendo considerablemente notoria la densidad de cuestiones comunes adquirida por ambos países a través de las relaciones bilaterales. Asimismo, Rusia se hizo presente en el mencionado escenario ocupando un lugar cada vez más gravitante en las relaciones internacionales de Argentina. También en un muy breve período, el lazo con Moscú fue enormemente intenso hasta el punto en el cual Rusia se convirtió en actor constante del radar de la diplomacia de Buenos Aires. Estas potencias no occidentales al entornar el bilateralismo entre Argentina y Estados Unidos, de un modo u otro, fueron un claro soporte externo del país latinoamericano.

El apoyo que China y Rusia le brindaron a Argentina, uno en cuestiones económicocomerciales y otro en cuestiones político-diplomáticas, no tuvo la fuerza que el país periférico requería para operar con poder. Los aportes de estas potencias no occidentales para que Argentina afirmara sus discrepancias hacia Estados Unidos en cuestiones de desarrollo interno y de vinculaciones con países considerados hostiles por Washington, como Irán y Venezuela, fueron discretos. La tentativa de ejercicio autonomista de política exterior, no logró restarle valor dominante a la potencia hegemónica. Es cierto que Estados Unidos no prestó asistencia para negocios e inversiones en Argentina, ni colaboró para morigerar la litigiosidad de los holdouts en el momento en el cual Buenos Aires lo requería, tampoco promovió la compra de más y diversos productos del país periférico,

8 Al respecto ver Roberto Bouzas (2009), Sergio Cesarín (2010), Carlos Escudé (2011) y Eduardo Oviedo (2015). 
sobre todo con valor agregado. Pero también es cierto que el esfuerzo de China como de Rusia a favor de aquellos temas preocupantes para Argentina, no fue diferente a la actitud adoptada por Estados Unidos.

La agenda de la política exterior argentina no tuvo modificaciones sustanciales. La sociedad con China y Rusia fue, sin duda, importante. Sin embargo, ambas representaron una condición necesaria, pero no suficiente para sostener la política exterior autonomista. Una y otra reprodujeron mecanismos políticos similares a los utilizados por el hegemón. El gobierno argentino creyó que había diferencias conceptuales entre las grandes potencias cuando en realidad no era así. Una vez más las actitudes y acciones de política exterior de cada uno contrastaron con la retórica y la intención que patrocinaron. China y Rusia priorizaron sus intereses separadamente de las aspiraciones de Buenos Aires. No hubo costos y beneficios recíprocos, propio de la interdependencia asimétrica. En suma, Argentina a través de las relaciones bilaterales con las mencionadas potencias no occidentales, no construyó poder para sostener en el tiempo la independencia decisional que su gobierno buscó ansiosamente frente a Estados Unidos.

\section{REFERENCIAS}

Bekerman, M. y Cerdeiro, D. (2007). Crisis y patrón de especialización comercial en economías emergentes. El caso de Argentina. Problemas del Desarrollo. Revista Latinoamericana de Economía, 38 (150), 133-165.

Bouzas, R. (2009). China y Argentina: relaciones económicas bilaterales e interacciones globales. En
AA.vv., China-Latinoamérica: una visión sobre el nuevo papel de China en la región (pp. 283-301). México DF: Instituto de Investigaciones Jurídicas de la Unam.

Cesarín, S. (2010). China y Argentina: enfoques y recomendaciones de politica para potenciar la relación bilateral. Buenos Aires: Fundación Ebert.

Corigliano, F. (2011). La política exterior del gobierno de Cristina Fernández de Kirchner: una típica política peronista del siglo xxI. Mural Internacional, Año II, (1), 22-27.

Costantino, A. (2013). ¿Gatopardismo sojero? Los efectos de la bonanza sojera sobre el cambio estructural de Argentina y Brasil. Nueva Sociedad, 244, 84-96.

Escudé, C. (2011). China y la inserción internacional de Argentina. Buenos Aires: Universidad del Cema, Documento de Trabajo, 462.

Falcoff, M. (2004). Argentina y Estados Unidos: Retorno al desencuentro histórico. En AA.Vv., Relaciones bilaterales entre Argentina y Estados Unidos. Pasado y presente. Washington: Woodrow Wilson International Center for Scholars.

Figari, G. (1985). Pautas para la elaboración de una política exterior argentina de carácter autonomista. Nuevo Mundo, 29-30.

Flanagan, S. (2017). Building resilience in Japan-China ties: a role for Australia. Canberra: Australian Defence College, Centre for Defence and Strategic Studies.

Gilley, B. (2011). Middle powers during great power transitions. China's rise and the future of CanadaUs. International Journal, 66 (2), 245-264.

Gil Villegas, F. (1989). El estudio de la política exterior en México: enfoques dominantes, temas principales y una propuesta teórico-metodológica. Foro Internacional, 116, 662-692. 
Gratius, S. (2017). El papel de la Unión Europea en el triángulo Cuba, Estados Unidos y Venezuela. IdeAs, 10, 1-18.

Hurrell, A. (2013). The Quest for Autonomy. The Evolution of Brazil's Role in the International System $1964-$ 1985. Brasilia: Fundação Alexandre de Gusmão.

Jaguaribe, H. (1979). Autonomía periférica y hegemonía céntrica. Estudios Internacionales, 46, 91-130.

Leiteritz, R. (2012). China and Latin America: A Marriage Made in Heaven? Colombia Internacional, 75, 49-81.

Leiva van de Maele, D. (2017). Russia is back: análisis de la evolución de la política exterior rusa en la “era Putin”. Estudios Internacionales, 187, 9-42.

Llenderrozas, E. (2011). La política exterior de los gobiernos kirchneristas. En AA.Vv., La politica en tiempos de los Kirchner (pp. 251-261). Buenos Aires: Eudeba.

Mazzina, C. y González Cambel, M. (2018). Continuidades y cambio de la política exterior del kirchnerismo y el gobierno de Cambiemos. PostData, 23, 1, 181-212.

Miranda, R. (2003). Politica exterior argentina. Idas y venidas entre 1999 y 2003. Rosario: Ediciones PIA.

Miranda, R. (2014). El rol político de Estados Unidos en el default de Argentina. Austral. Revista Brasileira de Estratégia e Relaçoes Internacionais, 3 (5), 227-246.

Oviedo, E. (2015). El ascenso de China y sus efectos en la relación con Argentina. Estudios Internacionales, $180,67-90$

Pavlova, E. (2011). Latinoamérica y Rusia. Foreign Affairs Latinoamérica, 11 (2), 57-67.
Puig, J.C. (1971). La vocación autonomista en América Latina. Heterodoxia y secesionismo. Revista de Derecho Internacional y Ciencias Diplomáticas, 37-38.

Russell, R. y Tokatlian, J. (2013). Implications of the Global and Regional Changes for Argentina's Foreign Relations. Journal of Iberian and Latin American Research, 19 (2), 251-267.

Schunz, S. (2010). How to Assess the European Union's Influence in International Affairs: Addressing a Major Conceptual Challenge for Eu Foreign Policy Analysis. Journal of Contemporary European Research, 6 (1), 22-42.

Sevares, J. (2007). ¿Cooperación Sur-Sur o dependencia a la vieja usanza? América Latina en el comercio internacional. Nueva Sociedad, 207, 11-22.

Shcherbakova, A. (2016). El comercio entre Rusia y Argentina: Tendencias recientes. Iberoamérica, 4, 54-67.

Sullivan, M. y Nelson, R. (2015). Argentina: Background and U.S. Relations, Congressional Research Service, agosto.

The New York Times. (13/03/2008). Rice Trip to Skip Argentina in Sign of a Growing Rift. October 19, 2011. Disponible en https://www.nytimes. com/2008/03/13/world/americas/13rice.html

The Washington Post. (26/12/2007). A Bagman's Tale; Did Hugo Chavez Purchase the Allegiance of Argentina’s New Presidente? June 17, 2011. Disponible en http://www.washingtonpost. com/wp-dyn/content/article/2007/12/25/ AR2007122500871.html 
Thoker, P. y Singh, B. (2017). The Emerging China, Pakistán, and Russia Strategic Triangle: India’s New Gordian Knot. Jadavpur Journal of International Relations, 21 (1), 61-83.

Torres, M. (2013). Argentina y su inserción internacional en un período de recuperación. Los principales cursos de acción de la política exterior del gobierno de Kirchner. Ciencia Politica, 8 (15), 107-135.
Womack, B. (2004). Asymmetry Theory and China's. Concept of Multipolarity. Journal of Contemporary China, 13 (39), 351-366.

Yákovlev, P. (2010). Rusia-Argentina: La etapa actual de las relaciones bilaterales. Iberoamérica, 3, 12-16. 